\title{
Reversibility of pulmonary arterial hypertension in HIV/HHV8-associated Castleman's disease
}

\author{
D. Montani*, L. Achouh*, A.G. Marcelin\#, J-P. Viard", O. Hermine+, D. Canioni", \\ O. Sitbon*, G. Simonneau* and M. Humbert*
}

ABSTRACT: The present study describes a case of pulmonary arterial hypertension (PAH) associated with multicentric Castleman's disease in a patient infected with HIV type 1 and human herpes virus 8 .

Therapy included highly active antiretroviral therapy, warfarin, diuretics, continuous i.v. epoprostenol and 12-monthly pulses of cyclophosphamide.

The patient's condition improved dramatically with complete reversibility of $\mathrm{PAH}$, allowing weaning of continuous i.v. epoprostenol therapy. After 5 yrs, both Castleman's disease and PAH have not relapsed. This supports the hypothesis that control of inflammation and retroviral replication may be of interest in the context of PAH, complicating the course of an inflammatory condition associated with viral infection.

In conclusion, further studies should help in characterising the best candidates for antiinflammatory treatment in the setting of pulmonary arterial hypertension.

KEYWORDS: Castleman's disease, HIV, human herpes virus 8, pulmonary arterial hypertension

$\mathbf{P}$ ulmonary arterial hypertension (PAH) is a rare condition characterised by elevated pulmonary arterial resistance leading to right heart failure and death [1]. PAH can be sporadic, familial or related to other conditions, including connective tissue disease, congenital systemic-to-pulmonary shunts, portal hypertension, HIV infection and appetite suppressant exposure [2]. Treatment of PAH allows improved survival, although current therapies do not achieve a cure for this devastating disease [3]. Complete reversibility of PAH has been exceptionally reported, mostly in the setting of active autoimmune diseases, such as systemic lupus erythematosus treated with corticosteroids and/ or immunosuppressive agents [4].

Castleman's disease is a rare clinical-pathological entity, belonging to the lymphoproliferative disorders and responsible for lymph node enlargement $[5,6]$. It can be classified into two forms: localised and multicentric. Localised disease is generally asymptomatic or presents as an isolated enlarged lymph node. Multicentric Castleman's disease often results in diffuse lymphadenopathy, frequently associated with hepatosplenomegaly and systemic manifestations (asthenia, weight loss and fever). Castleman's disease is defined by lymphocytic angiofollicular hyperplasia usually associated with polyclonal lymphocytic proliferation. There are no specific biological markers of Castleman's disease. However, in the multicentric forms, an elevation of the sedimentation rate, anaemia, thrombopenia and polyclonal hypergammaglobulinaemia can be observed $[5,6]$. Multicentric Castleman's disease has been associated with HIV infection [7]. The treatment of choice of localised forms is complete surgical resection with a strong possibility of cure without relapse. In multicentric forms there is no current therapeutic consensus, but most authors recommend chemotherapy. The prognosis of the multicentric forms is less favourable, with a cure in only $20 \%$ of cases $[5,6]$.

Only two cases of PAH and Castleman's disease have previously been reported in HIV seronegative patients [8]. In the present report, an additional case of severe PAH and multicentric Castleman's disease in an HIV-infected patient is described. The clinical course of this patient was remarkable with complete $\mathrm{PAH}$ reversibility with
AFFILIATIONS

${ }^{*}$ Centre des Maladies Vasculaires Pulmonaires, UPRES EA2705,

Service de Pneumologie et

Réanimation respiratoire, Hôpital Antoine-Béclère, Université ParisSud, and

\#Service de Virologie, Hôpital PitiéSalpétrière, and

"Service des Maladies Infectieuses, +Service d'Hématologie, and

${ }^{\S}$ Service d'Anatomie Pathologique, Groupe hospitalier Necker-Enfants Malades, Assistance PubliqueHôpitaux de Paris, Paris, France.

CORRESPONDENCE

M. Humbert

Centre des Maladies Vasculaires

Pulmonaires

UPRES EA 2705

Service de Pneumologie et

Réanimation Respiratoire

Hôpital Antoine Béclère

Assistance Publique-Hôpitaux de Paris

Université Paris-Sud

157 rue de la Porte de Trivaux 92140 Clamart

France

Fax: 33146303824

E-mail: marc.humbert@abc.aphop-paris.fr

Received:

November 232004

Accepted after revision:

April 262005 
medical treatments, which included highly active antiretroviral agents, 12 cyclophosphamide i.v. pulses and transient continuous i.v. epoprostenol.

\section{CASE REPORT}

A 31-yr-old female was admitted to the intensive care unit (Hôpital Antoine-Béclère, Assistance Publique Hôpitaux de Paris, France) in September 1997 after an episode of syncope. She was known to have had HIV-1 infection since 1988, presumably contracted after a blood transfusion. The patient did not have any history of opportunistic infections and had not received any antiretroviral treatment.

The electrocardiogram at admission showed sinus tachycardia, right ventricular hypertrophy and incomplete right bundle branch block. A chest radiograph demonstrated cardiac hypertrophy and enlarged pulmonary arteries. Echocardiography detected elevated systolic pulmonary arterial pressure (Ppa) of $11.97 \mathrm{kPa}(90 \mathrm{mmHg})$ and a paradoxal motion of the interventricular septum. Clinical examination revealed dyspnoea of functional class III of the New York Heart Association (NYHA), signs of right-heart failure and diffuse lymphadenopathy.

High-resolution computed tomography of the chest revealed enlarged pulmonary arteries and cardiomegaly without enlargement of the thoracic lymph nodes. A ventilation and perfusion lung scan was normal, ruling out a possible diagnosis of pulmonary thrombo-embolic disease. Right-heart catheterisation established the diagnosis of severe $\mathrm{PAH}$ with a mean $P$ pa of $8.51 \mathrm{kPa}(64 \mathrm{mmHg})$, pulmonary artery wedge pressure of $1.06 \mathrm{kPa}(8 \mathrm{mmHg})$ and a decreased cardiac index (2.4 L $\cdot \mathrm{min}^{-1} \cdot \mathrm{m}^{-2}$; table 1 ; fig. 1$)$. An acute vasodilatator challenge was negative $(0 \%$ change in mean $P$ pa and $1 \%$ increase in pulmonary vascular resistance after a 10 -min inhalation of $10 \mathrm{ppm}$ nitric oxide through a face mask). The 6-min walk distance (6MWD) was $295 \mathrm{~m}$.

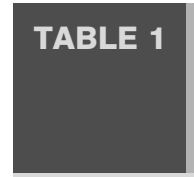

Haemodynamic parameters and functional status of a 31-yr-old HIV-positive patient with severe pulmonary arterial hypertension and Castleman's disease

\begin{tabular}{|c|c|c|c|c|c|}
\hline & $01 / 1998$ & 07/1998 & 11/1998 & 02/1999 & 10/2002 \\
\hline $\begin{array}{c}\text { Ppa systolic/diastolic/ } \\
\text { mean } \mathrm{mmHg}\end{array}$ & $92 / 50 / 64$ & $29 / 14 / 19$ & $32 / 18 / 23$ & $33 / 44 / 22$ & NA \\
\hline $\mathrm{Cl} / \mathrm{CO} \mathrm{L} \cdot \mathrm{min}^{-1} \cdot \mathrm{m}^{-2}$ & 2.4/3.6 & $3.4 / 5.3$ & $4.4 / 7.0$ & $3.9 / 6.3$ & NA \\
\hline TPR dynes $\cdot \mathbf{s} \cdot \mathrm{cm}^{-5}$ & 1422 & 287 & 263 & 279 & NA \\
\hline PVR dynes $\cdot \mathbf{s} \cdot \mathrm{cm}^{-5}$ & 1200 & 166 & 160 & 190 & NA \\
\hline Ppaw & 10 & 8 & 9 & 7 & NA \\
\hline $\mathrm{Sv}, \mathrm{O}_{2}$ & 48 & 71 & NA & 70 & NA \\
\hline Echo $s P$ pa mmHg & 90 & NA & NA & NA & 35 \\
\hline NYHA class & III & 1 & 1 & I & 1 \\
\hline 6MWD m & 295 & 490 & 505 & 490 & 472 \\
\hline
\end{tabular}

Ppa: pulmonary arterial pressure; Cl: cardiac index; CO: cardiac output; TPR: total pulmonary resistance; PVR: pulmonary vascular resistance; Ppaw: pulmonary artery wedge pressure; $\mathrm{Sv}, \mathrm{O}_{2}$ : mixed venous oxygen saturation; SPpa: systolic pulmonary artery pressure; NYHA: New York Heart Association; 6MWD: 6-min walk distance; NA: not available. $1 \mathrm{kPa}=\mathrm{mmHg} \times 0.133$

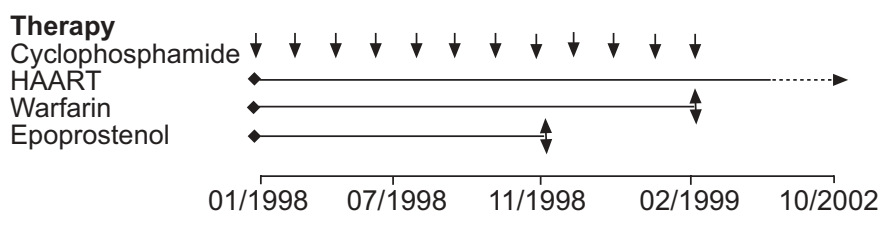

FIGURE 1. Treatment of a 31-yr-old HIV-positive patient with severe pulmonary arterial hypertension and Castleman's disease. Therapy included 12-monthly cyclophosphamide pulses, highly active antiretroviral therapy (HAART), warfarin and continuous i.v. epoprostenol.

Biological analysis found a polyclonal hypergammaglobulinaemia $\left(91.4 \mathrm{~g} \cdot \mathrm{L}^{-1}\right)$. CD4 lymphocyte count was $640 \mathrm{~mm}^{-3}$ and HIV-1 viral load was $4.9 \log 10$ copies $\cdot \mathrm{mL}^{-1}$. Abdominal ultrasound revealed hepatomegaly and renal cortico-medullary de-differentiation. Hepatic and renal biopsies showed plasmocyte infiltrates and renal arterial hyalinosis. The association of diffuse lymphadenopathy, polyclonal hypergammaglobulinaemia and plasmocytic infiltrates established the diagnosis of a multicentric Castleman's disease in an HIV patient, with severe PAH. Human herpes virus 8 (HHV8) serology was positive using a lytic immunoflurescence assay (HHV8 immunoglobulin G IFA; Biotrin, Dublin, Ireland).

Therapy included highly active antiretroviral therapy (initially AZT, 3TC, saquinavir, ritonavir, allowing full control of viral replication within 3 months), warfarin, diuretics, continuous i.v. epoprostenol and specific treatment of Castleman's disease, consisting of monthly i.v. pulses of $600 \mathrm{mg} \cdot \mathrm{m}^{-2}$ cyclophosphamide. After 3 months of therapy, the patient improved dramatically (NYHA functional class II and 6MWD of $440 \mathrm{~m}$ ). At 6 months, the patient's condition had clinically and haemodynamically normalised (NYHA functional class I, 6MWD of $490 \mathrm{~m}$, mean Ppa of $2.52 \mathrm{kPa}(19 \mathrm{mmHg})$ with a normal cardiac index of $3.40 \mathrm{~L} \cdot \mathrm{min}^{-1} \cdot \mathrm{m}^{-2}$; fig. 1$)$. After 10 months, the haemodynamic and clinical parameters were still stable, and epoprostenol was gradually weaned. A further 6 months later, the haemodynamic parameters remained stable (fig. 1). After 12 pulses of cyclophosphamide, the patient presented with complete remission of Castleman's disease and normal myelogram. Thus, cyclophosphamide therapy was discontinued. At present, 5 yrs after epoprostenol weaning, the patient is still asymptomatic and both Castleman's disease and $\mathrm{PAH}$ have not relapsed. Control echocardiography shows a stable systolic $P$ pa of $4.65 \mathrm{kPa}(35 \mathrm{mmHg})$ with a normal rightheart morphology.

\section{DISCUSSION}

Two cases of PAH in patients with multicentric Castleman's disease have previously been reported in the literature [8]. Both cases tested negative for HIV. The first patient presented with severe PAH and multicentric disease, but died of rightheart failure despite continuous i.v. prostacyclin therapy and complete remission of Castleman's disease. PAH improved in the second patient with dual endothelin receptor antagonist bosentan, without complete remission of the Castleman's disease. The patient in the present study is remarkable for two reasons: 1) this is the first case of PAH related to HIV infection in a patient with multicentric Castleman's disease; and 2) this patient had completely normalised pulmonary haemodynamics after treatment, including highly active 
antiretroviral agents, 12 cyclophosphamide i.v. pulses and transient continuous i.v. epoprostenol.

PAH and Castleman's disease are two rare conditions. Previous case reports in three patients raise several hypotheses linking these diseases. In Castleman's disease, interleukin (IL)6 , a multifunctional pro-inflammatory cytokine, is produced in large quantities in the germinal centres of hyperplastic lymph nodes [9]. Clinical manifestations of Castleman's disease are closely related to serum levels of IL-6, and IL-6 overproduction could explain hypergammaglobulinaemia and increased serum levels of acute phase proteins [9]. Indeed, systemic manifestations of multicentric Castleman's disease and its biological markers of inflammation can be alleviated after antiIL-6 receptor antibody therapy [10, 11]. IL-6 may also play a role in angiogenesis and could play a role in human, as well as experimental models of pulmonary hypertension [10, 12, 13]. These facts raise the possibility of IL- 6 being a common pathogenic factor in both PAH and Castleman's disease.

In addition, a viral link could explain why both conditions may coexist. Indeed, HIV and HHV8 have been reported to be involved in the pathophysiology of PAH and Castleman's disease. HHV8 is a vasculotrope virus associated with Kaposi's sarcoma and lymphoproliferative disease, including HIVassociated Castleman's disease and primary effusion lymphoma. HHV8 encodes genes homologous to human genes involved in cell proliferation, anti-apoptosis and angiogenesis. Viral genes, such as v-Cyclin or LANA-1 induce transcription of cell cycle genes via interaction with retinoblastom protein freeing a gene regulation protein, E2F [14, 15]. Furthermore, HHV8 genes are able to block apoptosis by inhibition of p53induced apoptosis (LANA-1) [16], inhibition of Fas-induced apoptosis (v-FLIP) [17] or inhibition of bax-mediated virally induced apoptosis (v-bcl2) [18].

In multicentric Castleman's disease, genetic sequences of HHV8 have been detected in $>60 \%$ of $\mathrm{HIV}$-infected patients and in $20-40 \%$ of HIV sero-negative cases [19]. Moreover, a strong correlation between HHV8 viral load and clinical symptoms, as well as elevated C-reactive protein and plasma IL-6 concentrations, was shown in multicentric Castleman's disease occurring in HIV-infected patients [20]. In PAH, HHV8 antigen and gene sequences have been found in plexiform lesions raising the possibility that HHV8 could be involved in the misguided angiogenesis characteristic of the disease [21]. Indeed, it has recently been demonstrated that HHV8 is able to produce a viral homologue of IL- 6 which shares many biological activities of human IL- 6 and promotes angiogenesis by inducing vascular endothelial growth factor (VEGF) expression [22-24]. Interestingly, VEGF has also been involved in the pathobiology of PAH $[25,26]$. However, recent analyses on plasma samples and lung tissues of patients with PAH do not plead in favour of an association between PAH and HHV8 [27-30]. Thus, additional information is still necessary to establish the true link between HHV8 infection and PAH.

The present study shows an unusual complete reversibility of both multicentric Castleman's disease and severe PAH, with a treatment regiment including a potent immunosuppressive agent (cyclophosphamide), together with highly active antiretroviral therapy and continuous i.v. epoprostenol. The respective role of each of these therapies in this unusual patient outcome needs to be discussed further. First, epoprostenol improves haemodynamics and exercise capacity in PAH [3]. However, haemodynamic and clinical improvements are far from complete. PAH reversibility leading to weaning of vasodilator therapy has not been reported in large cohorts of $\mathrm{PAH}$ patients, including idiopathic PAH and PAH related to HIV infection [31-34]. Therefore, it is recommended that $\mathrm{PAH}$ patients in NYHA functional class III or IV should receive lifelong vasodilator therapy [3]. Secondly, highly active antiretroviral therapy may result in significant clinical and haemodynamic effects in PAH related to HIV infection [33, 34]. However, these positive results are not sufficient to reverse this severe condition and it is recognised that NYHA functional class III or IV patients with PAH related to HIV should receive combined vasodilator therapy and highly active antiretroviral therapy $[3,33,35]$. Finally, inflammatory mechanisms appear to play a significant role in $\mathrm{PAH}$ of various origins in humans, such as systemic lupus erythematosus, mixed connective tissue disease, HIV infection or plasma cell dyscrasia with polyneuropathy, organomegaly, endocrinopathy, $\mathrm{M}$ protein and skin changes (POEMS syndrome) [36]. Interestingly, some patients with severe PAH associated with systemic lupus erythematosus and POEMS syndrome have experienced significant improvements with corticosteroids or immunosuppressive therapy, emphasising the relevance of inflammation in a subset of patients presenting with PAH [4, 37]. The present study supports the hypothesis that control of inflammation and retroviral replication may be of interest in the context of $\mathrm{PAH}$, complicating the course of an inflammatory condition associated with HIV infection.

In conclusion, further studies should help in characterising the best candidates for anti-inflammatory treatment in the setting of pulmonary arterial hypertension.

\section{REFERENCES}

1 Rubin LJ. Primary pulmonary hypertension. N Engl J Med 1997; 336: 111-117.

2 Simonneau G, Galie N, Rubin LJ, et al. Clinical classification of pulmonary hypertension. J Am Coll Cardiol 2004; 43: Suppl. 12, 5S-12S.

3 Humbert M, Sitbon O, Simonneau G. Treatment of pulmonary arterial hypertension. N Engl J Med 2004; 351: 1425-1436.

4 Sanchez O, Humbert M, Sitbon O, Simonneau G. Treatment of pulmonary hypertension secondary to connective tissue diseases. Thorax 1999; 54: 273-277.

5 Herrada J, Cabanillas F, Rice L, Manning J, Pugh W. The clinical behavior of localized and multicentric Castleman disease. Ann Intern Med 1998; 128: 657-662.

6 Peterson BA, Frizzera G. Multicentric Castleman's disease. Semin Oncol 1993; 20: 636-647.

7 Oksenhendler E, Duarte M, Soulier J, et al. Multicentric Castleman's disease in HIV infection: a clinical and pathological study of 20 patients. Aids 1996; 10: 61-67.

8 Bull TM, Cool CD, Serls AE, et al. Primary pulmonary hypertension, Castleman's disease and human herpesvirus8. Eur Respir J 2003; 22: 403-407. 
9 Yoshizaki K, Matsuda T, Nishimoto N, et al. Pathogenic significance of interleukin-6 (IL-6/BSF-2) in Castleman's disease. Blood 1989; 74: 1360-1367.

10 Nishimoto N, Sasai M, Shima $Y$, et al. Improvement in Castleman's disease by humanized anti-interleukin-6 receptor antibody therapy. Blood 2000; 95: 56-61.

11 Beck JT, Hsu SM, Wijdenes J, et al. Brief report: alleviation of systemic manifestations of Castleman's disease by monoclonal anti-interleukin-6 antibody. $N$ Engl J Med 1994; 330: 602-605.

12 Humbert M, Monti G, Brenot F, et al. Increased interleukin1 and interleukin-6 serum concentrations in severe primary pulmonary hypertension. Am J Respir Crit Care Med 1995; 151: 1628-1631.

13 Miyata M, Sakuma F, Yoshimura A, Ishikawa H, Nishimaki T, Kasukawa R. Pulmonary hypertension in rats. 2. Role of interleukin-6. Int Arch Allergy Immunol 1995; 108: 287-291.

14 Radkov SA, Kellam P, Boshoff C. The latent nuclear antigen of Kaposi sarcoma-associated herpesvirus targets the retinoblastoma-E2F pathway and with the oncogene Hras transforms primary rat cells. Nat Med 2000; 6: 1121-1127.

15 Swanton C, Mann DJ, Fleckenstein B, Neipel F, Peters G, Jones N. Herpes viral cyclin/Cdk6 complexes evade inhibition by CDK inhibitor proteins. Nature 1997; 390: 184-187.

16 Friborg J Jr, Kong W, Hottiger MO, Nabel GJ. p53 inhibition by the LANA protein of KSHV protects against cell death. Nature 1999; 402: 889-894.

17 Thome M, Schneider P, Hofmann K, et al. Viral FLICEinhibitory proteins (FLIPs) prevent apoptosis induced by death receptors. Nature 1997; 386: 517-521.

18 Cheng EH, Nicholas J, Bellows DS, et al. A Bcl-2 homolog encoded by Kaposi sarcoma-associated virus, human herpesvirus 8, inhibits apoptosis but does not heterodimerize with Bax or Bak. Proc Natl Acad Sci USA 1997; 94: 690-694.

19 Soulier J, Grollet L, Oksenhendler E, et al. Kaposi's sarcoma-associated herpes virus-like DNA sequences in multicentric Castleman's disease. Blood 1995; 86: 1276-1280.

20 Oksenhendler E, Carcelain G, Aoki Y, et al. High levels of human herpesvirus 8 viral load, human interleukin-6, interleukin-10, and C reactive protein correlate with exacerbation of multicentric castleman disease in HIVinfected patients. Blood 2000; 96: 2069-2073.

21 Cool CD, Rai PR, Yeager ME, Hernandez-Saavedra D, Serls AE, Bull TM. Expression of human herpesvirus 8 in primary pulmonary hypertension. N Engl J Med 2003; 349: 1113-1122.

22 Aoki Y, Jaffe ES, Chang Y, et al. Angiogenesis and hematopoiesis induced by Kaposi's sarcoma-associated herpesvirus-encoded interleukin-6. Blood 1999; 93: 4034-4043.
23 Cohen T, Nahari D, Cerem LW, Neufeld G, Levi BZ. Interleukin 6 induces the expression of vascular endothelial growth factor. J Biol Chem 1996; 271: 736-741.

24 Nishi J, Maruyama I. Increased expression of vascular endothelial growth factor (VEGF) in Castleman's disease: proposed pathomechanism of vascular proliferation in the affected lymph node. Leuk Lymphoma 2000; 38: 387-394.

25 Humbert M, Morrell NW, Archer SL, et al. Cellular and molecular pathobiology of pulmonary arterial hypertension. J Am Coll Cardiol 2004; 43: Suppl. 12, 13S-24S.

26 Eddahibi S, Humbert M, Sediame S, et al. Imbalance between platelet vascular endothelial growth factor and platelet-derived growth factor in pulmonary hypertension. Effect of prostacyclin therapy. Am J Respir Crit Care Med 2000; 162: 1493-1499.

27 Daibata M, Miyoshi I, Taguchi H, et al. Absence of human herpesvirus 8 in lung tissues from Japanese patients with primary pulmonary hypertension. Respir Med 2004; 98: 1231-1232.

28 Henke-Gendo C, Schulz T, Hoeper M. HHV-8 in pulmonary hypertension. N Engl J Med 2004; 350: 194-195.

29 Laney AS, De Marco T, Peters JS, et al. Kaposi sarcomaassociated herpesvirus and primary and secondary pulmonary hypertension. Chest 2005; 127: 762-767.

30 Montani D, Marcelin AG, Sitbon O, Calvez V, Simonneau G, Humbert M. Human herpes virus 8 in HIV and non-HIV infected patients with pulmonary arterial hypertension in France. AIDS 2005; 19: 1239-1240.

31 Sitbon $\mathrm{O}$, Humbert $\mathrm{M}$, Nunes $\mathrm{H}$, et al. Long-term intravenous epoprostenol infusion in primary pulmonary hypertension: prognostic factors and survival. J Am Coll Cardiol 2002; 40: 780-788.

32 McLaughlin VV, Shillington A, Rich S. Survival in primary pulmonary hypertension: the impact of epoprostenol therapy. Circulation 2002; 106: 1477-1482.

33 Nunes H, Humbert M, Sitbon O, et al. Prognostic factors for survival in human immunodeficiency virus-associated pulmonary arterial hypertension. Am J Respir Crit Care Med 2003; 167: 1433-1439.

34 Zuber JP, Calmy A, Evison JM, et al. Pulmonary arterial hypertension related to HIV infection: improved hemodynamics and survival associated with antiretroviral therapy. Clin Infect Dis 2004; 38: 1178-1185.

35 Sitbon O, Gressin V, Speich R, et al. Bosentan for the treatment of human immunodeficiency virus-associated pulmonary arterial hypertension. Am J Respir Crit Care Med 2004; 170: 1212-1217.

36 Dorfmuller P, Perros F, Balabanian K, Humbert M. Inflammation in pulmonary arterial hypertension. Eur Respir J 2003; 22: 358-363.

37 Lesprit P, Godeau B, Authier FJ, et al. Pulmonary hypertension in POEMS syndrome: a new feature mediated by cytokines. Am J Respir Crit Care Med 1998; 157: 907-911. 